among metropolitan Atlanta children were studied at the University of Kentucky, Lexington, KY, and Centers for Disease Control and Prevention, USPHS, Atlanta, GA, using data from the Metropolitan Atlanta Developmental Disabilities Study. The lifetime prevalence of LGS at age 10 years was $0.26 / 1000$, accounting for $4 \%$ of all childhood epilepsy. Mental retardation (IQ <70) was present in $91 \%$, and a history of infantile spasms in 39\%. Of children with profound mental retardation $(I Q<20)$ in Atlanta, $17 \%$ had LGS. LGS causes a disproportionate degree of morbidity and health care costs among children with epilepsy because of the multiple complications, including cerebral palsy, mental retardation, visual and hearing impairments, status epilepticus, and frequent falls with injury. (Trevathan E, Murphy CC, Yeargin-Allsopp. Prevalence and descriptive epidemiology of Lennox-Gastaut syndrome among Atlanta children. Epilepsia Dec 1997;38:12831288). (Reprints: Dr E Trevathan, Epilepsy Center, Department of Neurology, University of Kentusky, Kentucky Clinic, Room L-445, Lexington, KY 40536).

COMMENT. The prevalence of Lennox-Gastaut syndrome in a population based study among Atlanta children is 0.26/1000, and 4\% of all childhood epilepsy. The relatively high morbidity and increased health care costs of treating childhood LGS should prompt multicenter collaborative research projects to identify etiological risk factors, preventive measures, and more effective therapy.

See Progress in Pediatric Neurology III, 1997;pp82-83, for previous reports

of the prevalence of epilepsy: 6/1000 among 10-year-old children in Atlanta (Murphy CC et al, 1995), and 9.8/1000 among children <15 years in Rochester, MN (Hauser WA, 1994).

\title{
PREVALENCE OF EPILEPTIC SYNDROMES IN FINLAND
}

The prevalence of epilepsy and types of seizures and epileptic syndromes in children in the district of the Tampere University Hospital (population 175,000) and 34 surrounding rural counties was determined by a retrospective review of medical records and EEG recordings, using the latest ILAE International Classifications. Prevalence of epilepsy in 1992 was 3.94 per 1000 , and 96\% of seizures and $90 \%$ of epileptic syndromes could be classified. Generalized seizures and syndromes were more prevalent in young children 0-6 years of age, and partial/localization-related seizures in older children 6-15 years. Intractable epilepsies in $17 \%$ of all cases correlated with symptomatic etiology and early onset of seizures. Lennox-Gastaut accounted for $2 \%$ of epilepsies, and $10 \%$ were unclassified. (Eriksson KJ, Koivikko MJ. Prevalence, cl;assification, and severity of epilepsy and epileptic syndromes in children. Epilepsia Dec 1997;38:1275-1282). (Reprints: Dr KJ Erilsson, Tampere University Hospital, Department of Pediatrics, PO Box 2000, FIN-335621 Tampere, Finland).

COMMENT. Intractable seizures account for $17 \%$ of all epilepsies in a defined population of children in Finland. The prevalence of childhood epilepsy in the Finland population $(3.94 / 1000)$ is much lower than that in Atlanta $(6 / 1000)$ and Rochester, MN, USA $(9.8 / 1000)$.

\section{PHENOBARBITAL FOR CHILDHOOD EPILEPSY IN RURAL INDIA}

The acceptability of phenobarbital as a first-line drug for childhood epilepsy in rural settings in developing countries was studied using a randomized comparison of phenobarbital and phenytoin as monotherapy in West Bengal, India, and results were analyzed at the Institute of Child Health, University College London, UK, the MRC Biostatistics Unit, Cambridge, and Child-in-Need Institute, Daulutpur, West Bengal, India. Phenobarbital $(1.5 \mathrm{mg} / \mathrm{kg}$ daily for 2 
weeks; $3.0 \mathrm{mg} / \mathrm{kg}$ daily maintenance dose; $\mathrm{n}=47$ ) compared to phenytoin $(2.5$ $\mathrm{mg} / \mathrm{kg}$ daily increasing to $5.0 \mathrm{mg} / \mathrm{kg}$ daily; $\mathrm{n}=47$ ) showed no difference in efficacy over a 12 month period, and no excess of behavioral side-effects for phenobarbital based on Conners parent rating scales. (Pal DK, Das T, Chaudhury G, Johnson AL, Neville BGR. Randomised controlled trial to assess acceptability of phenobarbital for childhood epilepsy in rural India. Lancet Jan 3, 1998;351:19-23). (Respond: Dr Deb K Pal, Neurosciences Unit, Institute of Child Health, University College London, Wolfson Centre, London WC1N 2AP, UK).

COMMENT. Phenobarbital appears to be an acceptable first-line treatment for childhood epilepsy in a rural community in India. Compared to phenytoin, phenobarbital is equal in efficacy and has no excess of behavioral side effects. The WHO recommendation of phenobarbital for the treatment of partial and generalized tonic-clonic epilepsies in developing countries is justified. Phenytoin is slightly more expensive whereas carbamazepine and sodium valproate cost many times more than phenobarbital and generally require much closer monitoring. The reported behavioral side effects of phenobarbital may be overestimated in comparison with alternative antiepileptic drugs.

\section{ATTENTION DEFICIT DISORDERS}

\section{ACUTE HEPATIC FAILURE WITH PEMOLINE (CYLERT)}

A 7-year-old boy with Duchenne muscular dystrophy and ADHD who developed acute hepatic failure with autoimmune hepatitis during treatment with pemoline ( $56 \mathrm{mg} /$ day) is reported from the Children's Hospital, Cincinnati, OH. He presented with fever, vomiting, and jaundice, with thrombocytopenia and petechiae, after a period of decreased appetite. Ten-fold elevations of serum alanine aminotransferase (399 U/L) and aspartate aminotransferase (367 U/L) had been noted prior to pemoline treatment and 8 months prior to admission with hepatic failure. These may be ascribed to the muscle disease but could be consistent with pre-existing liver disease. On admission, these enzymes were markedly elevated, 1816 and $1313 \mathrm{U} / \mathrm{L}$, respectively, and the total and direct bilirubin levels were 104 and $56 \mathrm{mcmol} / \mathrm{L}$, respectively. Tests for hepatitis A and B were negative, but an autoimmune antibody panel, liver biosy findings, and coexistent diabetes were consistent with autoimmune hepatitis. After treatment with methylprednisolone, signs of encephalopathy gradually resolved, and at 2 year follow-up enzyme levels were moderately elevated (197 and 133, respectively) but one half the initial levels before pemoline administration. (Hochman JA, Woodard SA, Cohen MB. Exacerbation of autoimmune hepatitis: another hepatotoxic effect of pemoline therapy. Pediatrics Jan 1998;101:106-108). (Respond: Mitchell B Cohen MD, Children's Hospital Medical Center, OSB Building, 4th Floor, 3333 Burnet Ave, Cincinnati, OH 45229).

COMMENT. Since reports of acute liver failure associated with pemoline, the drug is no longer recommended as first-line therapy for ADHD. Pemoline has been linked to hepatic failure in 4 reported and a number of unreported cases. The liver toxicity is dose-dependent or due to an immune mediated hypersensitivity. The above case suggests an autoimmune process due to the drug, since pemoline withdrawal and treatment with prednisone resulted in a prompt response that was sustained after steroids were tapered. An analysis of pemoline associated hepatic failure (Shevell M, Schreiber R, Jan 1997) suggested that only one of the 4 reported cases appeared justified. Abbott Laboratories subsequently issued a warning and notice of further cases. (Ped Neur Briefs March 1997). 